\title{
Article
}

\section{Outcomes and Well-being Part 1: A comparative longitudinal study of two models of homecare delivery and their impact upon the older person self- reported subjective well-being}

Gethin-Jones, Stephen

Available at http://clok.uclan.ac.uk/2974/

Gethin-Jones, Stephen (2012) Outcomes and Well-being Part 1: A comparative longitudinal study of two models of homecare delivery and their impact upon the older person self-reported subjective well-being. Working with Older People, 16 (1). pp. 22-30. ISSN 1366-3666

It is advisable to refer to the publisher's version if you intend to cite from the work. http://dx.doi.org/10.1108/13663661211215141

For more information about UCLan's research in this area go to http://www.uclan.ac.uk/researchgroups/ and search for <name of research Group>.

For information about Research generally at UCLan please go to http://www.uclan.ac.uk/research/

All outputs in CLoK are protected by Intellectual Property Rights law, including Copyright law. Copyright, IPR and Moral Rights for the works on this site are retained by the individual authors and/or other copyright owners. Terms and conditions for use of this material are defined in the policies page. 


\section{Outcomes and well-being part 1: a comparative longitudinal study of two models of homecare delivery and their impact upon the older person self-reported subjective well-being}

Stephen Gethin-Jones

Stephen Gethin-Jones is a Senior Lecturer at the University of Central Lancashire, Preston, UK.

\begin{abstract}
Purpose - This paper aims to report on a study of outcome-focussed care for older people in one English local authority. The aim of the research is to examine whether altering the delivery of care to an outcome-focused model would improve the individual participant's subjective well-being and save money for the local authority.

Design/methodology/approach - In order for the aim of the research to be established, a pilot study was devised. This was a longitudinal study over 18 months, using a quantitative design. The sample was of 40 service users aged 65 and over whom all had critical and substantial care needs. Half of the sample of service users was receiving the new form of outcome-focused care and the other half were a comparison group who were receiving care packages according to the traditional form of delivery that could be characterised as a "task-focused" model. The service users were administered the Measure Yourself Concerns and Wellbeing Questionnaire (MYCAW). This questionnaire involves respondents identifying quality of life issues; where they are seeking improvement; and measures change over time in relation to these.

Findings - The research established that there was a greater improvement in subjective well-being in the group receiving outcome-focussed care, when compared with the comparison group receiving the traditional task-focused model.
\end{abstract}

Practical implications - This paper will assist managers in their decision making to implement a more outcome-focused model of home care with older people.

Originality/value - To use MYCAW in a social care context is an innovative aspect of this study as it has previously been used only in mainstream and complementary medicine. The focus of this paper is to examine the impact of two models of home care delivery for older people, and how these two models impact on the older persons' self-reported well-being.

Keywords Outcome-focus homecare, Older people, Social care, Home care

Paper type Research paper

\section{Background}

Maintaining the individuals' ability to live independently has been the main thrust of public policy for older people within the UK since the end of the Second World War (Bebbington and Charnley, 1990). However, within the UK the thrust of social care policy for homecare 
services has been aimed at the promotion of the individuals' physical functional ability. The focus on the physical ability is based on the premise that this would also boost the older adults' quality of life (Kutner et al., 1992; Lawton, 1991). The emphasis on physical functional ability has led to a task-focused approach to the delivery of homecare services to older people. This model divides the activities of daily living (Roper et al., 1980) into time tasked slots of 15 minutes, which enables private and state providers to cost their services and allow the commissioners of these services to purchase services on behalf of the service user through a process of care management (Challis et al., 2002). This model of care has been successful in enabling individuals to be maintained in their own homes and limit the cost to the state of long-term healthcare provision.

However, research conducted by the Social Policy Research Unit (York University) led by Qureshi et al. (1998) and Qureshi and Henwood (2000) noted service user and social worker dissatisfaction with the current model of delivery and developed a model of care that was outcome rather than tasked focused. This model has been piloted in the UK urban local authority and compared against the existing task-focused model. The focus of this pilot was to establish if the use of outcome-focused care improved the individuals' subjective wellbeing (SWB) over the existing model. Outcome-focused care is established by an agreement on appropriate outcomes that can be measured by the social worker and the service user, rather than purely agreeing tasked focused approach based on physical care. Therefore, the two parties' allocate time within which these outcomes could be achieved rather than time slotted tasks. This model allowed the individual the flexibility to bank time which could be used to meet their desired outcomes. An example of this is where an 88-year-old lady banked enough time to be taken to her husbands' grave which she had been unable to visit for three years. This model achieved this by the individual and the home-care worker agreeing which tasks could be reduced or curtailed (without detriment to the individual) in order for time to be built up to an agreed maximum of five hours.

Homecare within the UK developed historically around a domestic model of household chores. These chores would involve the provision of cooking and cleaning and would be seen as tasks of care which avoided the undertaking of activities that could be considered to involve any element of emotional care. This left the completion of tasks considered to be of an intimate and emotional nature (caring) to the remit of the family, with an underpinning belief that social support and intimate care would be provided by the female members within these families (Leece, 2003). In situations where families could no longer look after their elderly relatives the expectation was that the voluntary sector would support the individual out of "neighbourliness" or a sense of doing good. Therefore, it was hoped that communities rather than the state would provide support to the family. If these two models of homecare failed then the individual would be placed into some form of residential care provided by the local authority (Means and Smith, 1998). During the post-war period the welfare state continued to take on more of the responsibility for care to reflect the changing structure of the family and the profound social changes in the structure of communities and individuals' increased life expectancy.

\section{Method}

The quantitative data gathering utilised two validated questionnaires: Measure Yourself Medical Outcomes Profile (MYMOP) (Paterson, 1996), Measure Yourself Concerns and Wellbeing (MYCAW) (Paterson et al., 2007). These two instruments had been validated extensively in primary health care and were based on the larger SF-36 health survey (Ware et al., 1994). The designers purpose in developing these two questionnaires was to provide a tool that would enable practitioners to measure changes in self-identified outcomes of patients, and to establish what factors impacted upon their sense of physical and mental wellbeing. In addition to the questions posed in the MYMOP and MYCAW questionnaires some additional questions were added to enable the study to measure the level of social isolation and satisfaction with the paid care provided. The questionnaires were administered face to face by the same researcher. 


\section{Sample}

The sample size consisted $(n=40)$ participants. The participants were divided into two cohorts, one cohort being the intervention group: outcome-focused care $(n=20)$ and the other group being a control group: time/task $(n=20)$. All participants were aged over the age of 65 and were assessed as having care needs that were critical and substantial (Fair Access to Care Services, Department of Health, 2002). The participants were experiencing severe physical difficulties which impacted upon their ability to self care and ultimately live independently. No service users were accepted onto the study if they were considered to lack mental capacity as defined in the Mental Capacity Act (2005).

\section{Gender and age distribution}

The sample $(n=40)$ was distibuted females $(n=23)$ and males $(n=17)$ this distibution would be expected given the mean age of the sample (76.45) as women tend to live longer than their male counterparts in the UK. This division of gender is also supported by the research of Scharf et al. (2001) also examining the quality of life in old age with 58 per cent of their sample being female and having a similar mean age of 71.53. This would allow for some confidence in the sample despite its limited size and that these findings might have the potential to be generalised to the wider older poulation.

\section{Individuals' self-reported physical and SWB scores}

Diener's (2009) concept of SWB is an accepted measure for the measurement of wellbeing in old age. The Berlin Ageing Study (Baltes and Mayer, 1999) has conducted longitudinal studies of wellbeing in old age utilising Diener's concept of SWB. This study focused on the same age group (70-100+) as in this study, with an emphasis on the examination of wellbeing in participants in their third and fourth age. The sample size was large $(n=517)$ and looked, as does this paper, at psychological, social and physiological factors impacting upon older persons and their sense of SWB.

The MYCAW questionnaire also utilised Diener's single item question on wellbeing and then added two further questions allowing the participants to self-identify their two main non-medical concerns. The purpose of the MYCAW concern measure was to provide a multi-item scale when considering the individuals' SWB, and to allow a deeper analysis of the factors that were impacting upon the participants' emotional wellbeing. This paper will also examine physical self-identified wellbeing with the MYMOP questionnaire, in order to consider if the changes in the individuals' physical health have either a positive or negative association with how the individuals rate their SWB. Multi-item scales are considered to provide a more accurate measure of wellbeing than single item scales. A number of multi-item assessment tools have been developed to assess older people's SWB, these being the geriatric SWB scales developed by Diener (1984), with Diener arguing that having scales that are particular to a client group is more effective in establishing SWB in particular age ranges. These scales, although considered to be effective in measuring SWB in older people, are quite lengthy and are designed for the general older population. As this particular piece of research was with frail older people, it was felt that these larger scales would be overly intrusive and difficult to complete in the allotted timescale stipulated by the local authorities' ethics committee. However, the fact that Diener's concept of SWB has been applied across national boundaries and to different population groups, which has resulted in similar findings being established, gives some confidence that the use of scales based on Diener's work will provide some face validity to the findings. This also allows for the findings from this research to be compared to other research on older people utilising the same scale.

The MYMOP questionnaire allowed the service user to identify two physical problems that were of the most concern to them. These physical incapacities could be broken down into three main categories. The first category could be seen a physical mechanical problems induced by degenerative bone conditions and the severe pain this induces $(n=18)$. The second category could be seen a physical mobility problems induced by neurological conditions such as strokes and balance or dizziness issues caused by circulatory problems 
with these combined conditions ( $n=12$ ). The final main category revolved around the loss of sight $(n=9)$, with one service users mobility problems being attributed to clinical obese.

The distribution of incapacities appears to be similar across the two groups. This would allow for some confidence that the groups' physical profiles are similar and would provide some confidence in the two groups' representation of the wider social services service user older population.

The MYCAW document asked the participants to identify issues that concerned them. These have been categorized in Tables I and II. The first concern is the primary concern affecting their SWB the most with Concern 2 being the concern of secondary importance.

The MYCAW questionnaire asked the participants to identify these two concerns in addition to their self-rated measurement of wellbeing. The participants could choose anything that concerned them and therefore each response was very individual and subjective. Therefore, in order for any analysis to take place each response was placed within three broad categories. The first category, which had the highest number of respondents $(n=20)$ was the inability to go out, to either visit friends or participate in activities such as church-going or visiting the pub. Not surprisingly, the second category that scored highest was that of loneliness $(n=16)$. The third category was the inability to care for self or others $(n=15)$.

Table III shows that, when Categories 1 and 2 are combined, the responses across the two groups are very similar, with the inability to leave the house scoring the highest number of responses, followed by similar scores for loneliness and inability to care for self or others. We can see that the greatest concerns are the inability to go out, followed by loneliness. Therefore, consideration needs to be given to the type of activity that the different types of intervention provide: for example, the outcome-focused intervention by its ability to conduct tasks outside physical care allows more time for the individual to get out of the house, then this might explain whether it was this aspect of the intervention that had the greatest impact. Again, this was not a question posed in the questionnaire and will be analysed in future research.

When a statistical analysis was conducted (ANOVA) there does appear to be a strong association between the type of intervention the participants received and their SWB score.

Table I Outcome-focused interventions: participants' self-identified concerns

\begin{tabular}{|c|c|c|c|c|}
\hline Participant ID & Age & Gender & Concern 1 & Concern 2 \\
\hline OFRE75 & 75 & Female & Not having family support & Inability to go out \\
\hline OFAL80 & 80 & Female & Not getting out into the garden & Having someone who understands me \\
\hline OFAJ65 & 65 & Female & Constantly different staff & No relationship with the staff \\
\hline OFGJ79 & 79 & Male & Not being able to care for my wife & $\begin{array}{l}\text { Not being able to lift my wife and her having to go } \\
\text { into a home }\end{array}$ \\
\hline OFMB77 & 77 & Female & Loneliness & Not being able to go to church \\
\hline OFMJ89 & 89 & Female & Not being able to look after myself & Not being able to go out everyday \\
\hline OFBN92 & 92 & Female & Not being able to go out and meet friends & $\begin{array}{l}\text { Not being able to be involved in church } \\
\text { activities }\end{array}$ \\
\hline OFPC80 & 80 & Male & Being stuck in the house & Not being able to meet friends in the labour club \\
\hline OFDL74 & 74 & Male & Not being able to read or watch TV & Not going to my local pub \\
\hline OFAT73 & 73 & Male & People constantly asking me questions & Different people visiting everyday \\
\hline OFRB66 & 66 & Male & Being dependent on others & Feeling lonely \\
\hline OFST81 & 81 & Male & Not going out & Becoming so ill I cannot stay in my own home \\
\hline OFNB69 & 69 & Male & Feeling a burden to my family & Feeling lonely \\
\hline OFFB78 & 78 & Female & Inability to visit my husband in the care home & Feeling lonely \\
\hline OFPB70 & 70 & Female & Inability to go into the garden & $\begin{array}{l}\text { Not being able to go out and meet up with } \\
\text { friends }\end{array}$ \\
\hline OFVK88 & 88 & Female & Not being able to hold my grandchild & Not being able to look after my sister \\
\hline OFAS96 & 96 & Male & Lonely, not being able to go out & Not being able to watch TV \\
\hline OFEL76 & 76 & Female & Not being able to care for my pets & Loneliness \\
\hline OFBF77 & 77 & Female & Not being able to cook & $\begin{array}{l}\text { Not being able to go out and shop for clothes with } \\
\text { my friend }\end{array}$ \\
\hline OFFB82 & 82 & Female & Loneliness and becoming totally housebound & Not being able to go to church \\
\hline
\end{tabular}


Table II Time/task participants' self-expressed concerns (MYCAW)

\begin{tabular}{|c|c|c|c|c|}
\hline$I D$ & Age & Gender & Concern 1 & Concern 2 \\
\hline TTMF70 & 70 & Male & Not having relationship with my wife & $\begin{array}{l}\text { No dignity, different people washing and showering } \\
\text { me }\end{array}$ \\
\hline TTGL97 & 97 & Female & So lonely & No activity in my life \\
\hline TTIA72 & 72 & Male & Not being able to go to the pub & Forgetting things around the house \\
\hline TTLT74 & 74 & Male & Not being able to keep on top of the garden & $\begin{array}{l}\text { Losing contact with friends as I cannot get out as } \\
\text { much }\end{array}$ \\
\hline TTDB71 & 71 & Female & Inability to look after my dog & Loneliness \\
\hline TTRH76 & 76 & Female & Can't go out on my own & Not being able to read any more \\
\hline TTEH69 & 69 & Female & Very lonely & Not being able to visit friends in their nursing home \\
\hline TTLO73 & 73 & Female & So lonely & Not being able to get to church \\
\hline TTHT78 & 78 & Male & Not being able to get to watch the football, so lonely & Walking with a stick makes me feel weak \\
\hline TTRAM81 & 81 & Female & My lifestyle, unable to meet friends & Feeling low and sad \\
\hline TTHH69 & 69 & Female & Losing touch with the outside world & Boredom and loneliness \\
\hline TTBB81 & 81 & Male & Difficulty watching TV or reading & $\begin{array}{l}\text { Not being able to visit my daughter and } \\
\text { granddaughter }\end{array}$ \\
\hline TTLS78 & 78 & Female & Not being able to go out on my own & Difficulty watching TV or reading \\
\hline TTAS79 & 79 & Male & $\begin{array}{l}\text { No major concerns except not being able to go to } \\
\text { the pub }\end{array}$ & $\begin{array}{l}\text { Having to be dependent on others, especially care } \\
\text { staff who are always changing }\end{array}$ \\
\hline TTBB69 & 70 & Female & Not being able to walk any distance & Isolation, being stuck in too much \\
\hline TTLN72 & 72 & Male & $\begin{array}{l}\text { Not being able to wash myself, the lack of dignity } \\
\text { with different staff doing it all the time }\end{array}$ & Isolation, not being able to go out \\
\hline TTRE73 & 73 & Male & Loss of independence & The stigma of walking with a frame \\
\hline TTMH66 & 66 & Male & Not being able to drive & Loneliness \\
\hline TTMW86 & 86 & Female & Not being able to look after my dog & Loneliness, not having any friends and family left \\
\hline TTRS67 & 67 & Male & Not being able to look after myself & Not being able to care of my grandchildren \\
\hline
\end{tabular}

Table III Self-identified concerns

\begin{tabular}{llcc} 
Categories & Descriptors for Concerns 1 and 2 & Outcome-focused & Time/task \\
\hline Category 1 & Inability to go out & 10 & 10 \\
Category 2 & Loneliness & 7 & 9 \\
Category 3 & Inability to care for self or others & 7 & 8 \\
Category 4 & No clear category & 5 & 4
\end{tabular}

In addition to an improvement in the individuals' SWB score there was a reduction in the level of concern identified by the individuals', with the concern scores also improving in the intervention group more than in the time/task group ( $p$-value being $>0.00$ ). Therefore, there appears to be a global improvement in the participants' overall wellbeing despite a slight decline in their physical health.

Interestingly, when the mean scores are analysed between the two groups as to how the individuals' self-rated physical wellbeing had been over the last week, Measures 1 and 2 demonstrated that the outcome-focused group's condition had deteriorated, whereas the time/task group score actually demonstrated a slight improvement. This finding appears to indicate that the individuals' physical health declining or slightly improving has not had an impact upon their SWB. However, this raises the question as to whether the intervention had contributed to the decline. When this was analysed, there did not appear to be an association, between physical health and the individual's self-reported SWB with the $p$-value being $>0.11$ which demonstrated there was no association between your physical health and your SWB.

\section{Benefits and costs of the different interventions}

This analysis was conducted in partnership with the local authorities' commissioning finance department. The areas analysed were the actual unit costs of the two interventions, and also 
whether the outcome-focused provision led to a reduction in hours required. The assumption made by the local authority was that, based on un-researched anecdotal evidence from other local authorities, the provision of outcome-focused care led to a reduction of hours from service users, as they were more selective over the hours they used and the unnecessary provision of tasks could be eradicated.

The first area considered was the pure financial cost of the two provisions. The finance department tracked the cost of six service users from the outcome-focused group and the time/task group. Service users were selected who had spent at least 18 months receiving their care packages and the number of hours used were measured at the start and finish point of the intervention (Figure 1).

The hours used did support the anecdotal evidence that the number of hours used by the service user did reduce more within the outcome-focus group than with the traditional time/task model. This data were gathered from the time sheets completed by the homecare workers, which identified how long they spent completing tasks with the participants. However, what is masked by these findings is the method of recording. It was noted that the time/task intervention workers recorded each task completed against a 15-minute time allocation, even if the task only took five minutes, whereas the outcome-focused group recorded the time actually spent with the participant, rather than the raw task time. Table IV shows the actual time spent with the participants and the time allocated; the table is again based on the group average.

Table IV clearly shows a difference in the time spent with service users. This makes outcomefocused care significantly more expensive than the time/task model for the service provider.

Figure 1 Average number of hours used per participant during the intervention period

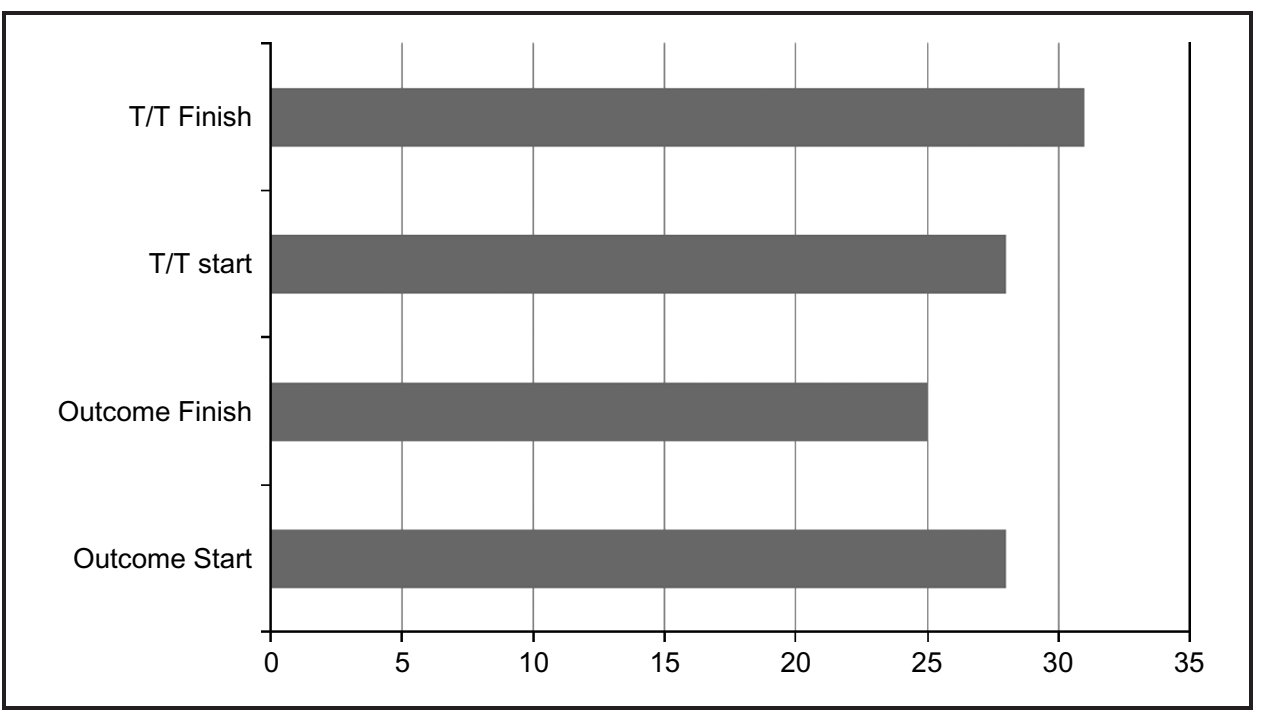

\section{Table IV Duration of paid care visits}

Of homecare worker 1

Of homecare worker 2

Of homecare worker 3

Of homecare worker 4

$\mathrm{T} / \mathrm{T}$ homecare worker 1

$\mathrm{T} / \mathrm{T}$ homecare worker 2

$\mathrm{T} / \mathrm{T}$ homecare worker 3

$\mathrm{T} / \mathrm{T}$ homecare worker 4 
However, this also demonstrates that the actual personnel contact time received by the outcome-focus group was significantly more than their task-focused counterparts. The time/ task provider is therefore able to see more service users in a day, and in this particular example the group of time/task homecare workers, by cutting corners on time, would be able to see two more service users in their working day. This in turn allows the agency contracted to lower their unit costs as they are being paid for more hours than they are completing. However, because the care plan stipulates tasks rather than hours to be completed, the agency is not breaching its contract. Therefore, services allocated based on time, as in this case, were 17 percent more expensive, even after the reduction in hours used by the outcome-focused group. This data were calculated by the finance department of the commissioners, and the researcher has not been supplied with the data on how this figure was calculated.

The findings from this analysis show that outcome-focused care participants receive considerably more human contact time with the homecare staff than do the time/task group participants. Because of the limited number of participants involved and because the calculations made to arrive at the cost figures were not supplied, it is impossible to explore this more here and is an area requiring further research.

\section{Key findings from this paper}

This paper has established that the participants have a mean age of 76.45 and are all experiencing severe physical problems induced by either physical disease, neurological impairment, or the loss of one or more of their senses. These incapacities have severely restricted the individuals' independence, so that the participants have a high level of dependency in order to live in the community and interact socially in the wider community. However, interestingly, an important finding was that, despite having family nearby, the majority of participants experienced very low levels of social contact, with their paid carers being the main source of social contact. The participants also demonstrated that the ability to establish a relationship with their carers was very important to them and that this was facilitated by the extra contact time provided by the outcome-focus care model.

The findings from the MYCAW and MYMOP questionnaires were also interesting. The questionnaire demonstrated that, despite individuals within the outcome-focused group indicating a decline in their physical wellbeing (MYMOP), they also demonstrated an improvement in their sense of SWB. More importantly, this data also demonstrated what appears to be an association between the type of intervention and the participants' SWB, inasmuch as those receiving the intervention of outcome-focused care showed the most significant improvement in their self-rated. Finally, the costs of the service analysis revealed that, despite the same amount of time being purchased for participants in both the outcome-focused group and the time/task group, the amount of time actually being delivered to these two groups varied considerably.

\section{Key themes to be developed}

A number of themes have been developed throughout this paper that require further analysis. These themes are:

- Social interaction.

- Loneliness.

- Relationship with paid staff.

- Wellbeing concerns identified by the participants.

These themes were identified as requiring furher investigation in future research, to allow for a deeper understanding of the mechanisms that were operating for each participant whether they were receiving the intervention of outcome-focused care or not. This emphasis on the mechanisms would give an understanding of what aspects of the outcome-focused

PAGE 28 $\mid$ WORKING WITH OLDER PEOPLE | VOL. 16 NO. 12012 
intervention worked that were not also provided by the traditional time/task model of 400 homecare delivery.

\section{Conclusion}

This paper has focused mainly on the "does" question. In examining the "does" question, it has been established that there is an association between the type of intervention the participant receives and their self-rated wellbeing. However, it is not clear why this is the case and therefore further qualitataive research, will allow for the context to be studied in greater depth to establish why this intervention appears to have an impact upon the individuals SWB.

- Move away from task-focused provision to person-centered services.

- Targeting of outcome-focused care to the most socially isolated.

- Greater focus on the holistic care of the service user rather than pure physical care.

\section{References}

Baltes, P.B. and Mayer, K.U. (1999), The Berlin Aging Study: Aging from 70-100, Cambridge University Press, New York, NY.

Bebbington, A. and Charnley, H. (1990), "Community care for the elderly: rhetoric and reality", British Journal of Social Work, Vol. 20, pp. 409-32.

Challis, D., Chesterman, J., Luckett, R., Stewart, K. and Chessum, R. (2002), Care Management in Social and Primary Health Care: The Gateshead Community Care Scheme, Arena, Aldershot.

Department of Health (2002), Fair Access to Care Services, available at: /www.dh.gov.uk/en/ consultations/responsestoconsultations/dh_4017186">http://webarchive.nationalarchives.gov.uk/+/ www.dh.gov.uk/en/Consultations/Responsestoconsultations/DH_4017186 (accessed 7 April 2011).

Diener, E. (1984), "Subjective well-being", Psychological Bulletin, Vol. 95, pp. 542-75.

Diener, E. (2009), The Science of Well-being: The Collected Works of Ed Diener, Springer, London.

Kutner, N.G., Ory, M.G., Baker, D.L., Schechtman, K.B., Hornbrook, M.C. and Mulrow, C.D. (1992), "Measuring the quality of life of the elderly in health promotion clinical trials", Public Health Reports, Vol. 107, pp. 530-9.

Lawton, M.P. (1991), "A multidimensional view of quality of life in frail elders", in Birren, J.E., Luben, J.E., Rowe, J.C. and Deutchman, D.E. (Eds), The Concept of the Measurement of Quality of Life in the Frail Elderly, Academic Press, San Diego, CA, pp. 3-27.

Leece, J. (2003), "The development of domiciliary care: what does the future hold?', Practice: Social Work in Action, Vol. 15 No. 3, pp. 17-30.

Means, R. and Smith, R. (1998), Community Care: Policy and Practice, 2nd ed., Macmillan Press, London.

Q1 Mental Capacity Act (2005), HMSO, London.

Paterson, C. (1996), "Measuring outcomes in primary care: a patient generated measure, MYMOP, compared with the SF-36 health survey", British Medical Journal, Vol. 312, pp. 1016-20.

Paterson, C., Thomas, K., Manasse, A., Cook, H. and Pearce, C. (2007), "Measure yourself concerns and wellbeing (MYCaW): an individualised questionnaire for evaluating outcome in cancer support care that includes complementary therapies", Complementary Therapies in Medicine, Vol. 15, pp. 38-41. 
Qureshi, H. and Henwood, M. (2000), Older People's Definitions of Quality Services, Joseph Rowntree Foundation, York.

Qureshi, H., Patmore, C. and Nicolas, E. (1998), "Overview of outcomes of social care for older people and carers", Report No. 5, Social Policy Research Unit, University of York, York.

Roper, N., Logan, W. and Tierney, A. (1980), The Elements of Nursing, Churchill Livingstone, Edinburgh.

Scharf, T. Phillipson, T and Kingston, P. (2001) "SN4695 - survey of quality of life in older age",

Ware, J., Kosinski, M. and Keller, S. (1994), SF-36 Physical and Mental Health Summary Scales: A User's 


\section{Author Queries}

JOB NUMBER: 145637

JOURNAL: WWOP

Dear Author

Please address all the numbered queries on this page which are clearly identified on the proof for your convenience.

Thank you for your cooperation

Q1

Please provide author name for reference Mental Capacity Act (2005) 